\title{
Antibiotic Susceptibility Pattern and Bacterial Spectrum Among Patients with External Eye Infections at Menelik II Referral Hospital in Addis Ababa, Ethiopia
}

\author{
Asmamaw Nitsuh Woreta $\mathbb{D}^{\text {1,2 }}$, Habtamu Biazin Kebede $\mathbb{D}^{1}$ ', Yonas Tilahun ${ }^{3}$, Solomon Gebreselassie Teklegiorgis ', \\ Woldaregay Erku Abegaz' \\ 'Department of Microbiology, Immunology and Parasitology, College of Health Sciences, Addis Ababa University, Addis Ababa, Ethiopia; \\ ${ }^{2}$ Microbiology Unit, Department of Laboratory Sciences, Menelik II Referral Hospital, Addis Ababa, Ethiopia; ${ }^{3}$ Department of Ophthalmology, College \\ of Health Sciences, Addis Ababa University, Addis Ababa, Ethiopia \\ Correspondence: Habtamu Biazin Kebede, Email habtamu.biazin@aau.edu.et
}

Background: Eye infections can cause loss or impairment of visual function and can lead to severe impairment. Bacteria are the most common pathogens that affect the structure of the eye. As a result, quick identification of the causative agents and testing of their medication susceptibility are essential for effective treatment of eye infections. This study was intended for determining the extent of bacterial isolates from external eye infections (EEIs) and their susceptibility to antibiotics.

Methods: A facility-based cross-sectional study was conducted among patients attending Menelik II Referral Hospital. The study comprised patients who had EEIs verified. EEI samples were collected using sterile methods. Bacterial isolates were identified using gram stain, colony morphology, and biochemical tests. The Kirby-Bauer disk diffusion technique was used to conduct a drug susceptibility test.

Results: Totally, 323 participants were recruited for this study and 184 bacterial isolates were obtained from 175 (54.5\%) participants. The main clinical diagnosis was blepharitis 122 (37.8\%), followed by conjunctivitis $73(22.6 \%)$ and keratitis $57(17.6 \%)$. The grampositive isolates were $171(92.9 \%)$. CoNS with a frequency of $76(41.3 \%)$ was the most common bacterial isolates, followed by $S$. aureus 67 (36.4\%), Viridans streptococcus 16 (8.7\%), and Klebsiella species 6(3.3\%). Gram-positive isolates were sensitive to tobramycin, gentamicin, chloramphenicol, vancomycin, and ceftriaxone. In contrast, $94.0 \%$ of these gram-positive isolates showed resistance to penicillin. Multidrug resistance (MDR) was observed in both gram-positive and negative bacteria at rates of 123 (72\%) and 12 (92.1\%), respectively. The overall MDR rate among the isolates was $135(73.4 \%)$.

Conclusion: In this study, blepharitis was the major EEI, followed by conjunctivitis. The predominant bacterial species isolated from EEIs were CoNS, followed by $S$. aureus. More than half of the isolates were drug-resistant, with a large number being multidrugresistant, highlighting the necessity for continued and coordinated surveillance to hunt for infections that are known to be resistant.

Keywords: external eye infection, bacterial isolate, antibiotic susceptibility status, Ethiopia

\section{Background}

Eye infections are common in most developing countries. ${ }^{1}$ Based on the site of infection, it can be divided into two main groups: external infections ((EEI) and intraocular infections. Both forms of infection can cause visual impairment and are a major health problem. ${ }^{2}$ Both are common causes of eye disease worldwide, including Ethiopia. ${ }^{3,4}$ The most common EEIs, such as conjunctivitis, blepharitis, keratitis, Dacryocystitis, orbital and periorbital cellulitis, are recognized forms of eye infections. Keratitis is an inflammation of the cornea that threatens vision. ${ }^{3,5}$

Various variables affect the development of bacterial EEI, including unsanitary conditions, socioeconomic conditions, living conditions, contact lens use, previous eye trauma, chronic epithelial defects, and immune status. ${ }^{6}$ In addition, ocular surface and eyelid epithelium are relatively impervious to microorganisms but factors that facilitate infections are 
trauma, surgery, or systemic disease. ${ }^{5}$ EEI can cause many signs and symptoms. The causative organism can result from a systemic infection carried by the external environment or blood. ${ }^{7}$ The normal bacterial community have a tremendous impact on the health of the external eyes. Their mechanisms and hosts regulate the normal microbial community of the eyelids and conjunctiva, and alterations in this normal bacterial community may contribute to ocular infections. ${ }^{8}$ Many opportunistic microorganisms are increasingly encountering ocular infections as a result of the extensive use of local and systemic immunosuppressants. ${ }^{9,10}$

The most essential pathogens in bacterial conjunctivitis are $S$. aureus and $S$. pneumonia. Pseudomonas aeruginosa and Proteus mirabilis have also been isolated less frequently from bacterial conjunctivitis samples. ${ }^{11-13}$ In many cases, a single infection with Gram-negative bacilli may predominate. Several different sorts of microorganisms may also be implicated in the pathogenesis of chronic lacrimal pouchitis (Dacryocystitis). Usually, the majority of the infected individuals harbor more than one microorganism. ${ }^{14}$ P. aeruginosa and S. aureus, on the other hand, are two of the most prevalent bacteria that cause microbial keratitis. ${ }^{9}$

Generally, infection of the eye can lead to loss or impairment of visual function causing major Disability. Hence, there is a need for immediate treatment for the serious bacterial eye infection that threatens visions of the eye. ${ }^{15,16}$ On the other hand, bacterial resistance has been emerging worldwide, concerning the irrational use of antimicrobial agents. ${ }^{17,18}$ Because bacterial aetiology, susceptibility, and resistance patterns differ depending on geographic location, ${ }^{19}$ locally generated up-to-date information is essential for appropriate antimicrobial therapy and management of eye infection. ${ }^{9}$ Although Menelik II Referral Hospital is a referral hospital designated for all ophthalmology related complicated diseases in Ethiopia, enough up-to-date published data are not found from this hospital on this topic. Therefore, this study aimed to determine antimicrobial susceptibility to bacterial eye infections, risk factors, and bacterial isolates in eye infections at Menelik II Referral Hospital.

\section{Methods and Materials}

\section{Study Design and Settings}

A health facility-based prospective cross-sectional study was implemented among patients suspected of external eye infections from January to April 2019 from Menelik II Referral Hospital, Department of Ophthalmology, and Addis Ababa, Ethiopia. Three hundred and twenty-three patients with suspected eye infections were enrolled in the study.

\section{Sample Size and Sampling Technique}

A single proportion formula was used to determine the sample size by considering $30 \%$ of the prevalence rate, which was documented previously. ${ }^{20}$ By taking the margin error (d) of 0.05 and $95 \%$ confidence interval, the calculation uses the following formula.

Sample size, where: $\mathrm{n}=\frac{(\mathrm{Z} \alpha / 2) 2 . \mathrm{P}(1-\mathrm{P})}{\mathrm{d} 2}$

Where:

$\mathrm{n}=$ the required sample size

$\mathrm{p}=$ proportion

$\mathrm{d}=$ Expected margin of error $=0.05$

$\mathrm{Z} \alpha / 2=95 \%$ confidence interval (C.I) $=1.96$

$\mathrm{p}=$ prevalence of the previous study found from literature review $=30 \%$.

Hence, $\mathrm{n}=\frac{(1.96) 2 \times 0.3 \times 0.7}{(0.05) 2}$

Therefore, 323 study participants were recruited. Sampling was done conveniently every other day from EEI confirmed patients who fulfilled the sampling criteria.

\section{Inclusion and Exclusion Criteria}

All ages and sex groups with the presence of EEI and who had inclined to offer their consent had been enrolled in the study. However, patients who had taken antibiotics for the last two weeks and those unwilling to give consent were excluded from the study. 


\section{Study Participants and Socio-Demographic Data}

Patients who visited the ophthalmology department, were clinically diagnosed with external eye infections, and met the eligibility criteria during the study period were included in the study. Selects were recruited prospectively based on thorough clinical examination by clinicians/ophthalmologists using a slit lamp biomicroscope to rule out inflammation. Only patients willing to give their consent were enrolled in the study. Structured questionnaires and physical examinations were used to collect demographic data (age, sex, monthly income, educational level, occupation, and address) and ophthalmic clinical data (history of repeated infections, length of stay in the hospital, use of contact lenses, surgery, previous antibacterial therapy, systemic diseases, and use of traditional medicine).

\section{Specimen Collection, Transportation and Processing}

Samples were collected prospectively from study participants following the standard practice of the hospital. A qualified ophthalmologist and ophthalmic nurse collected corneal scraping after instilling 2 to 3 drops of local anaesthetic (Tetra Caine hydrochloride $0.5 \%$ ) into the conjunctiva and waiting for 2 to 3 minutes. ${ }^{16}$ Conjunctival specimens were collected using a sterile cotton-tipped swab bypassing the swab gently over conjunctiva 2-times. ${ }^{3,11}$

Dacryocystitis and canaliculated pus were collected by applying pressure to the lacrimal sac using a dry sterile cotton swab. The primary swab was inoculated into Amie's transport medium and transported to the Microbiology Laboratory. Next, inoculate Brain Heart Infusion Broth (BHIB) for concentration and enrichment, subculture in 5\% sheep blood agar medium, MacConkey agar medium, chocolate agar medium, Mannitol salt agar medium, and subculture at $37^{\circ} \mathrm{C}$ and inoculated for 24-48 hours. Aerobic air conditions were maintained in MacConkey agar and Mannitol salt agar, and chocolate agar and 5\% sheep blood agar were cultured in a 5-10\% CO2 atmosphere. ${ }^{22}$ Finally, Gram staining, subculture and biochemical tests were done for species identifications. The isolates were then maintained in sterile BHIB mixed with glycerol for storage for further work.

\section{Antimicrobial Susceptibility Testing}

A modified Kirby-Bauer disk diffusion technique was done for drug susceptibility test (DST) on all identified bacterial isolates as recommended by Laboratory Standard Institutes ${ }^{21,23}$ on plain Mueller-Hinton agar non-fastidious isolates and Mueller-Hinton agar supplemented with 5\% defibrinated sheep blood for fastidious bacterial isolates. The bacterial suspension equivalent to the McFarland standard ( $0.5 \mathrm{CFU}$ ) was seeded on Muller-Hinton agar followed by putting antibiotic-impregnated disks on the agar suspension after a few minutes of delay (Oxoid Ltd Basingstoke, Hampshire, UK), and then incubating for $18-24$ hours at $37^{\circ} \mathrm{C}$. The inhibition zone of disk diameter was measured using a calliper and categorized as resistance, intermediate and, sensitive. According to the CLSI guideline 2017, the following antibiotics were tested against gram-positive bacterial isolates. Penicillin $(10 \mu \mathrm{g})$, Erythromycin $(15 \mu \mathrm{g})$, Cotrimoxazole $(1.25 / 23.75 \mu \mathrm{g})$, Cefoxitin $(30 \mu \mathrm{g})$, Gentamicin $(10 \mu \mathrm{g})$, Ciprofloxacin $(5 \mu \mathrm{g})$, Tobramycin $(10 \mu \mathrm{g})$, Chloramphenicol $(30 \mathrm{~g})$,

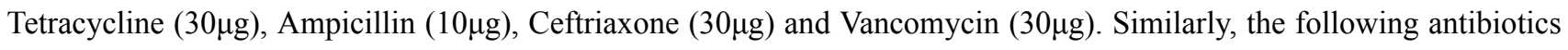
were tested against gram-negative isolates, Amikacin (30g), Ampicillin $(10 \mu \mathrm{g})$, Gentamicin $(10 \mu \mathrm{g})$, Cotrimoxazole (1.25/

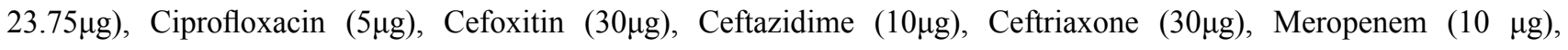
Tobramycin $(10 \mu \mathrm{g})$ and Chloramphenicol $(30 \mathrm{~g})$ Bacterial isolates which are resistant for at least one antibiotic from three or more classes of antibiotics were considered as multidrug-resistant (MDR). ${ }^{24}$

\section{Quality Control}

To maintain the quality of expected outcome, Standard Operating procedures (SOP) were strictly followed during sample collection, identification and susceptibility testing. Subsequently, Visual inspections were performed for the absences of cracks in media or plates, unequal fill, hemolysis, evidence of freezing, bubbles, and contamination. The sterility of culture media was then confirmed by overnight incubation of $5 \%$ of prepared media and observation of no growth from each batch. Finally, the prepared media and biochemical tests' abilities to support the growth of organisms were checked throughout the study by inoculating standard reference strains such as (ATCC ${ }^{\circledR}$ 29213) for S. aureus, (ATCC ${ }^{\circledR} 25922$ ), 
for E. coli, $\left(\mathrm{ATCC}^{\circledR}\right.$ 49226) for $N$. gonorrhoeae, $\left(\mathrm{ATCC}^{\circledR}\right.$ 700603) for $K$. pneumonia and $\left(\mathrm{ATCC}^{\circledR} 27853\right)$ for $P$. aeruginosa obtained from Ethiopian public health institute, Addis Ababa, Ethiopia. ${ }^{11,21,25}$

\section{Data Analyses}

Before data was collected, a standardized questionnaire was translated into the local language (Amharic). To produce high-quality and accurate data, all quality control checks were performed before, during, and after data collection. Then, every day, all of the data was entered into a Microsoft-Excel spreadsheet 2016 (Microsoft Cop., USA). Finally, the data were imported and analyzed with Statistical Product and Service Solutions (SPSS) version 25.0. (IBM, USA). Descriptive statistics were calculated, and data were presented in the form of figures and tables. Binary logistic regression was also used to show the association of different independent variables with the dependent variable (bacterial isolates). Moreover, a multivariate logistic analysis was computed to identify factors that independently influenced the occurrence of dependent variables (bacterial isolates) by determining the adjusted odds ratio. In all analyses, P-values less than 0.05 were considered significant.

\section{Ethical Considerations}

The study was evaluated and approved by the Research Ethics Review Committee of the Department of Microbiology, Immunology and Parasitology (DRERC) (Ref. No. /07/2019), and the Institutional Review Board (CHS-IRB) (Ref. No. IRB/012/2019) of Addis Ababa University. A support letter was secured from Addis Ababa Health Bureau; and College of Health Science, Addis Ababa University. Moreover, before commencing the study, written informed consent and/or assents were obtained from each participant or guardian. Subject confidentiality and any special data security requirements were maintained and assured.

Physicians were notified of the findings of laboratory testing that had a direct impact on the study participants' health, and the patients received their results when they returned for appointments or retreatments. Overall, the study protocol complies based on the Declaration of Helsinki.

\section{Results}

\section{Socio-Demographic Characteristics}

Three hundred and twenty-three patients with external eye infections were enrolled. The majority of the participants were males $186(57.6 \%)$ and the mean age was 40.9 years. About $143(44.3 \%)$ of the patients were over 45 years of age, and most of them 206 (63.8\%) were urban residents. The majority of 208/323 (64.4\%) study patients' educational status were shown primary school level and below. Patients aged 40-60, 31-45 years also showed higher culture-positive results 81 (25.1\%), and 69 (21.4\%), respectively. Regarding educational status, high culture positivity rates were observed, among elementary school and illiterates with the rate of $109(34 \%)$ and $81(25.1 \%)$, respectively.

In regards to participants' clinical data from 323 study participants, 59 (18.3\%) patients had a previous history of eye surgery and only $25(7.7 \%)$ individuals had the systemic disease. The dominant clinical feature was Blepharitis accounting for 122/323 (37.8\%), followed by conjunctivitis 73 (22.6\%) and Dacryocystitis 39 (12.1\%). According to their geographical location, 147 (45.5\%) were from Addis Ababa and 27.2\% of them were from Oromia, respectively (Table 1).

\section{The Magnitude of Bacterial Isolates and Clinical Features}

The ocular specimens of 323 ophthalmic patients were cultured in this investigation, and 175 (54.2\%) of them were culture positive. A total of 184 bacteria isolates were obtained and the majority of patients 166/175 (94.9\%) had a single bacterial isolate while only 9/175 (5.1\%) demonstrated mixed bacterial isolates. Among the isolates, 171 (92.9\%) were gram-positive and 13 (7.1\%) were gram-negative bacteria. Coagulase-negative Staphylococci (CoNS) were the predominant isolate 76/184 (41.3\%) followed by S. aureus 67/184 (36.4\%) and Streptococcus Viridian 16/184 (8.6\%).

Among culture-positive conjunctivitis, Blepharitis, Blepharo-conjunctivitis, and keratitis gram-positive bacteria were constituted 40/41 (98\%), 67/71 (94\%), 10/10 (100\%) and 31/33 (93.9\%), respectively. On the other hand, higher 
Table I Sociodemographic Characteristics of Study Participants

\begin{tabular}{|c|c|c|c|}
\hline \multicolumn{2}{|l|}{ Variables } & \multirow{2}{*}{$\frac{\text { Frequency }}{137}$} & \multirow{2}{*}{$\begin{array}{c}\% \\
42.4\end{array}$} \\
\hline Gender & Female & & \\
\hline & Male & 186 & 57.6 \\
\hline \multirow[t]{2}{*}{ Residence } & Rural & 117 & 36.2 \\
\hline & Urban & 206 & 63.8 \\
\hline \multirow[t]{6}{*}{ Geographical location } & Addis Ababa & 147 & 45.5 \\
\hline & Oromia & 88 & 27.2 \\
\hline & Amhara & 55 & 17 \\
\hline & SNNPR & 21 & 6.5 \\
\hline & Harari & 4 & 1.2 \\
\hline & Others & 8 & 2.4 \\
\hline \multirow[t]{8}{*}{ Occupation } & Preschool Children & 23 & 7.1 \\
\hline & Student & 32 & 9.9 \\
\hline & Farmer & 90 & 27.9 \\
\hline & House Wife & 33 & 10.2 \\
\hline & Labourer & 43 & 13.3 \\
\hline & Merchant & 23 & 7.1 \\
\hline & Employed & 75 & 23.2 \\
\hline & Unemployed & 4 & 1.2 \\
\hline \multirow{2}{*}{$\begin{array}{l}\text { History of any eye } \\
\text { trauma }\end{array}$} & Yes & 51 & 15.8 \\
\hline & No & 272 & 84.2 \\
\hline \multirow[t]{2}{*}{ Eyeglass uses } & Yes & 71 & 22 \\
\hline & No & 252 & 78 \\
\hline Total & & 323 & 100 \\
\hline
\end{tabular}

proportions of gram-negative bacterial isolates were obtained from Dacryocystitis 6/23 (26\%), Blepharitis 4/71 (5.6\%) and keratitis $2 / 33(6.1 \%)$. Among patients positive for bacterial isolates and clinically categorized as blepharitis $(\mathrm{n}=71)$, CoNS were the most common isolates occurring appearing in 36/71 (50.7\%) isolates followed by Staphylococcus aureus 23/71 (32.4\%) isolates. On the other hand, the proportion of Gram-negative bacterial isolates was 13/184 (7.1\%); especially, Klebsiella species 6/184 (3.3\%) were among the common gram-negative isolates (Table 2).

\section{Susceptibility to Antibiotics of Gram-Positive Bacterial Isolates}

Only 10/171 (2.9\%) of the Gram-positive bacterial isolates examined in this study showed no antimicrobial resistance to any of the drugs tested; an overwhelming majority of the isolates were resistant to one or more antibiotics. Among the 171 gram-positive bacterial isolates, relatively high susceptibility was observed to Tobramycin (94.4\%), Vancomycin (92.9\%). Among the S. aureus isolates, 65/67 (97.0\%) and 58/67 (86.5\%) were susceptible to Tobramycin and Gentamicin, respectively. On the other hand, significant amounts of gram-positive isolates had lower sensitivity (below 50\%) to penicillin (6.0\%), ampicillin (20.0\%), erythromycin (28.9\%), and Cotrimoxazole (36\%). Higher 
Table 2 The Distribution of Bacterial Isolates in External Eye Infection at Menelik II Referral Hospital, Ethiopia, 2019

\begin{tabular}{|c|c|c|c|c|c|c|c|}
\hline \multirow{2}{*}{$\begin{array}{l}\text { Isolated Bacterial Species } \\
\text { in Each Case }\end{array}$} & \multicolumn{6}{|c|}{ Categories of External Eye Infection $n$ (\%) } & \multirow{2}{*}{$\frac{\text { Total }}{323(100)}$} \\
\hline & $\begin{array}{c}\text { Conjunctivitis } \\
73(22.6)\end{array}$ & $\begin{array}{c}\text { Dacrocystitis } \\
39(12.1)\end{array}$ & $\begin{array}{c}\text { Blepharitis } \\
\text { 122(37.8) }\end{array}$ & $\begin{array}{c}\text { Keratitis } 57 \\
(17.6)\end{array}$ & BC I8(5.6) & $\begin{array}{c}\text { Other EOI } \\
14(4.3)\end{array}$ & \\
\hline \multicolumn{8}{|l|}{ Gram-positive isolates } \\
\hline Staphylococcus aureus & 18(43.9) & $7(30.4)$ & $23(32.4)$ & $12(37)$ & $5(50)$ & $2(33.3)$ & $67(36.4)$ \\
\hline CoNS & 14(34.1) & $7(30.4)$ & $36(50.7)$ & 13(39) & $3(30)$ & $3(50)$ & $76(41.3)$ \\
\hline$\beta$-Hemolytic Streptococci & 0 & 0 & 0 & I(3) & 0 & 0 & $\mathrm{I}(0.5)$ \\
\hline Streptococcus Viridans & $4(9.8)$ & $2(8.7)$ & $5(7)$ & $3(9)$ & $2(20)$ & 0 & $16(8.6)$ \\
\hline S. pneumoniae & $3(7.3)$ & 0 & $2(2.8)$ & $\mathrm{I}(3)$ & 0 & 0 & $6(3.3)$ \\
\hline Enterococcus Species & $\mathrm{I}(2.4)$ & $\mathrm{I}(4.3)$ & $\mathrm{I}(\mathrm{I} .4)$ & $\mathrm{I}(3)$ & 0 & $\mathrm{I}(16.7)$ & $5(2.7)$ \\
\hline Total isolates & $40(97.6)$ & $17(73.9)$ & $67(94.3)$ & $3 I(94)$ & $10(100)$ & $6(100)$ & $171(93)$ \\
\hline \multicolumn{8}{|l|}{ Gram-negative isolates } \\
\hline Escherichia coli & 0 & $\mathrm{I}(4.3)$ & 0 & 0 & 0 & 0 & $\mathrm{I}(0.5)$ \\
\hline Klebsiella Species & $I(2.4)$ & $3(13.1)$ & $2(2.8)$ & 0 & 0 & 0 & $6(3.3)$ \\
\hline Acinetobacter Species & 0 & $\mathrm{I}(4.3)$ & 0 & $\mathrm{I}(3)$ & 0 & 0 & $2(1.1)$ \\
\hline Proteus Species & 0 & $\mathrm{I}(4.3)$ & $\mathrm{I}(\mathrm{I} .4)$ & 0 & 0 & 0 & $2(1.1)$ \\
\hline P. aeruginosa & 0 & 0 & 0 & $\mathrm{I}(3)$ & 0 & 0 & $I(1.1)$ \\
\hline Providencia stuartii & 0 & 0 & $\mathrm{I}(\mathrm{I} .4)$ & 0 & 0 & 0 & $\mathrm{I}(1.1)$ \\
\hline Total isolates & $\mathrm{I}(2.4)$ & $6(26)$ & $4(5.6)$ & $2(6)$ & 0 & 0 & $13(7.1)$ \\
\hline Total bacterial species & $4 \mathrm{I}(22.3)$ & $23(\mid 2.5)$ & $71(38.6)$ & $33(17.9)$ & $10(5.43)$ & $6(3.3)$ & $184(100)$ \\
\hline
\end{tabular}

proportions of the S. aureus isolates had lower sensitivity to penicillin 2/67 (3.0\%) and Erythromycin 21/67 (31.3\%). The prevalence of MRSA, as determined based on the resistance pattern of Cefoxitin, was 23/67 (34.3\%).

Tobramycin was the only antibiotic to which CoNS isolates were highly sensitive, accounting for 70/76 (92.1\%); and for the rest three drugs CoNS isolates were sensitive to Gentamicin 50/76 (67\%), Chloramphenicol 45/76 (59.2\%), and to Cefoxitin 41/76 (53.9\%). All Enterococcus spp. and Streptococcus pneumoniae isolates 6/6 (100\%) were sensitive to Vancomycin (Table 3).

\section{Gram-Negative Bacterial Isolates' Antibiotic Susceptibility}

As of entire bacterial isolates, only 13 of them were gram-negative. All of these isolates 13/13 (100\%) were showed susceptibility to Tobramycin. In addition, the large majority of these isolates $11 / 13(84.6 \%)$ were susceptible to Gentamicin. While 10/13 (76.9\%) gram-negative bacterial isolates were equally susceptible towards Amikacin and ciprofloxacin. However, the vast majority of them were shown to have a low susceptibility rate towards Ampicillin 1/10 $(10 \%)$ and Cotrimoxazole $3 / 13$ (23.1\%). As far as the susceptibility of each specific isolate is concerned, Klebsiella spp. was completely 6/6 (100\%) susceptible to Meropenem and Tobramycin but demonstrated reduced susceptibility to Amikacin and Gentamicin with the rate of 5/6 (83.3\%) for both antibiotics (Table 4).

\section{Multidrug Resistance Patterns of Bacterial Isolates}

In this study, only 5(2.7\%) of isolates were sensitive for all classes of tested antibiotics; $18(9.8 \%)$ were resistant to one class of antimicrobials. The overall prevalence of multidrug resistance (bacteria resistant to at least one antibiotic from three or more classes) was 135/184 (73.4\%). 
Table 3 Antibiotic Susceptibility Pattern of Gram-Positive Bacteria Isolated from External Eye Infections at Menelik II Referral Hospital, Ethiopia, 20I9

\begin{tabular}{|c|c|c|c|c|c|c|c|c|c|c|c|c|c|}
\hline \multirow[t]{2}{*}{ Bacterial Isolates } & \multirow[t]{2}{*}{ Resistance Pattern } & \multicolumn{12}{|c|}{ Antibiotic Susceptibility Status N (\%) } \\
\hline & & PEN & ERY & GEN & СОт & CPR & $\mathbf{C X T}$ & тOB & CHL & TET & AMP & CFT & VAN \\
\hline \multirow[t]{3}{*}{ S. aureus } & $\mathrm{R}$ & $65(97)$ & $37(55.2)$ & $3(4.5)$ & $31(46.3)$ & II (16.4) & $23(34.3)$ & $2(3.0)$ & $11(16.4)$ & - & - & - & - \\
\hline & I & - & $9(13.4)$ & 6(9) & $\mathrm{I}(1.5)$ & $8(11.9)$ & - & 0 & $3(4.5)$ & - & - & - & - \\
\hline & S & $2(3.0)$ & $21(3 \mid .3)$ & $58(86.5)$ & $35(52.2)$ & $48(71.6)$ & $44(65.7)$ & $65(97.0)$ & $53(79.1)$ & - & - & - & - \\
\hline \multirow[t]{3}{*}{ CoNS } & $R$ & 75 (99) & $57(75)$ & $18(23.7)$ & $56(73.7)$ & $39(51.3)$ & $35(46.1)$ & $4(5.3)$ & $30(39.5)$ & - & - & - & - \\
\hline & I & - & $6(7.9)$ & $7(9.2)$ & $4(5.3)$ & $6(7.9)$ & - & $2(2.6)$ & $\mathrm{I}(\mathrm{I} .3)$ & - & - & - & - \\
\hline & $S$ & $\mathrm{I}(\mathrm{I} .3)$ & $13(17.1)$ & $50(67)$ & $16(21)$ & $3 I(40.8)$ & $4 I(53.9)$ & $70(92.1)$ & $45(59.2)$ & - & - & - & - \\
\hline \multirow[t]{3}{*}{ S. pneumoniae } & $\mathrm{R}$ & $I(16.7)$ & $I(16.7)$ & - & $2(33.3)$ & - & - & - & $2(33.3)$ & $2(33.3)$ & - & - & 0 \\
\hline & I & - & 0 & - & $I(16.7)$ & - & - & - & 0 & 0 & - & - & 0 \\
\hline & $S$ & $5(83.3)$ & $5(83)$ & - & $3(50)$ & - & - & - & $4(66.7)$ & $4(66.7)$ & - & - & $6(100)$ \\
\hline \multirow{2}{*}{$\begin{array}{l}\text { B hemolytic } \\
\text { Streptococci }\end{array}$} & $\mathrm{R}$ & 0 & 0 & - & $I(100)$ & - & - & - & $I(100)$ & $I(100)$ & - & - & 0 \\
\hline & S & $\mathrm{I}(100)$ & $\mathrm{I}(100)$ & - & 0 & - & - & - & 0 & 0 & - & - & $I(100)$ \\
\hline \multirow{3}{*}{$\begin{array}{l}\text { Streptococcus } \\
\text { viridans }\end{array}$} & $\mathrm{R}$ & - & $7(43.8)$ & - & - & - & - & - & $2(12.5)$ & - & - & $2(12.5)$ & $2(12.5)$ \\
\hline & I & - & $I(6.2)$ & - & - & - & - & - & 0 & - & - & $2(12.5)$ & 0 \\
\hline & S & - & $8(50)$ & - & - & - & - & - & $14(87.5)$ & - & - & $12(75)$ & $\begin{array}{l}14 \\
(87.5)\end{array}$ \\
\hline \multirow[t]{3}{*}{ Enterococcus Species } & $\mathrm{R}$ & - & - & - & - & $2(40)$ & - & - & - & - & $4(80)$ & - & 0 \\
\hline & I & - & - & - & - & 0 & - & - & - & - & - & - & 0 \\
\hline & $S$ & - & - & - & - & $3(60)$ & - & - & - & - & $\mathrm{I}(20)$ & - & $5(100)$ \\
\hline \multicolumn{2}{|l|}{ Total tested isolates } & 150 & 166 & 143 & 150 & 148 & 143 & 143 & 166 & 7 & 5 & 16 & 28 \\
\hline \multicolumn{2}{|c|}{ Resistance isolates $\mathbf{n}(\%)$} & $14 \mid(94)$ & $118(71.1)$ & $34(23.8)$ & $96(64)$ & $66(44.6)$ & $58(40.6)$ & $8(5.6)$ & $50(30.1)$ & $3(42.9)$ & $4(80)$ & $4(25)$ & $2(7.1)$ \\
\hline
\end{tabular}

Abbreviations: PEN, Penicillin; ERY, Erythromycin; GEN, Gentamicin; COT, cotrimoxazole; CPR, Ciprofloxacin; CXT, Cefoxitin; TOB, Tobramycin; CHL, Chloramphenicol; TET, Tetracycline; AMP, Ampicillin; CFT, Ceftriaxone; VAN, Vancomycin. 
Table 4 Antibiotic Susceptibility Pattern of Gram-Negative Bacteria Isolated from External Eye Infections at Menelik II Referral Hospital, Ethiopia, 2019

\begin{tabular}{|c|c|c|c|c|c|c|c|c|c|c|c|}
\hline \multirow{2}{*}{$\begin{array}{l}\text { Bacterial } \\
\text { Isolates }\end{array}$} & \multirow{2}{*}{$\begin{array}{l}\text { Level of } \\
\text { Pattern }\end{array}$} & \multicolumn{10}{|c|}{ Antibiotic Susceptibility Status N (\%) } \\
\hline & & AMK & AMP & GEN & СOT & CPR & CAZ & CFT & MER & TOB & CHL \\
\hline \multirow[t]{2}{*}{ Acinetobacter } & $\mathrm{R}$ & $\mathrm{I}(50)$ & - & I(50) & $2(100)$ & 0 & $2(100)$ & - & $\mathrm{I}(50)$ & 0 & - \\
\hline & S & $\mathrm{I}(50)$ & - & $\mathrm{I}(50)$ & 0 & $2(100)$ & 0 & - & $\mathrm{I}(50)$ & $2(100)$ & - \\
\hline \multirow[t]{2}{*}{ E. coli } & $\mathrm{R}$ & 0 & $\mathrm{I}(100)$ & 0 & $\mathrm{I}(100)$ & 0 & $\mathrm{I}(100)$ & 0 & $\mathrm{I}(100)$ & 0 & 0 \\
\hline & S & $I(100)$ & 0 & $I(100)$ & 0 & $I(100)$ & 0 & $I(100)$ & - & $I(100)$ & $I(100)$ \\
\hline Klebsiella & $\mathrm{R}$ & $\mathrm{I}(16.7)$ & $6(100)$ & $I(16.7)$ & $3(50)$ & 0 & $3(50)$ & $\mathrm{I}(16.7)$ & 0 & 0 & $2(33.0)$ \\
\hline \multirow[t]{2}{*}{ Species } & 1 & 0 & 0 & 0 & 0 & $2(33.3)$ & 0 & $2(33.3)$ & 0 & 0 & $I(16.7)$ \\
\hline & S & $5(83.3)$ & 0 & $5(83.3)$ & $3(50)$ & $4(66.7)$ & $3(50)$ & $3(50)$ & $6(100)$ & $6(100)$ & $3(50)$ \\
\hline \multirow[t]{2}{*}{ Proteus Species } & $R$ & 0 & $2(100)$ & 0 & $2(100)$ & 0 & 0 & $I(50)$ & $2(100)$ & 0 & $I(50)$ \\
\hline & S & $2(100$ & 0 & $2(100)$ & 0 & $2(100)$ & $2(100)$ & $I(50)$ & 0 & $2(100)$ & $I(50)$ \\
\hline \multirow[t]{2}{*}{ P. aeruginosa } & $\mathrm{R}$ & 0 & - & 0 & $I(100)$ & 0 & $I(100)$ & - & 0 & 0 & - \\
\hline & S & $I(100)$ & - & $I(100)$ & 0 & $\mathrm{I}(100)$ & 0 & - & $\mathrm{I}(100)$ & $I(100)$ & - \\
\hline \multirow[t]{2}{*}{ P. stuartii } & $\mathrm{R}$ & $I(100)$ & 0 & 0 & $I(100)$ & $I(100)$ & 0 & 0 & $I(100)$ & 0 & 0 \\
\hline & S & 0 & $I(100)$ & $I(100)$ & 0 & 0 & $I(100)$ & $I(100)$ & 0 & $\mathrm{I}(100)$ & $I(100)$ \\
\hline \multicolumn{2}{|c|}{ Total tested isolates } & 13 & 10 & 13 & 13 & 13 & 13 & 10 & 13 & 13 & 10 \\
\hline \multicolumn{2}{|c|}{ Resistance isolates n (\%) } & $3(23.1)$ & $9(90)$ & $2(15.4)$ & $10(86.9)$ & $3(23.1)$ & $7(53.8)$ & $4(40)$ & $5(38.5)$ & 0 & $4(40)$ \\
\hline
\end{tabular}

Abbreviations: AMK, Amikacin; AMP, Ampicillin; Gen, Gentamicin; COT, cotrimoxazole; CPR, Ciprofloxacin; CAZ, ceftazidime; CFT, Ceftriaxone; MER, Meropenem; TOB, Tobramycin; CHL, Chloramphenicol; S, sensitive; R, resistant; I, Intermediate. 
Among the gram-positive isolates, 123/171 (72\%) had multidrug resistance. Similarly, most of the gram-negative bacterial isolates 12/13 (92.3\%) demonstrated multidrug resistance. The leading multi-drug resistant gram-positive isolates were CoNS with the rate of 70/76 (92\%) followed by S. aureus isolates with the rate of 45/67 (67.2\%). The prevalence of MRSA, as determined based on the resistance pattern of Cefoxitin, was 23/67 (34.3\%). However, the lowest 1/5 (20\%) multidrug resistance observed among the gram-positive isolates were from the Enterococcus species. In this study, there were no XDR and PDR isolates detected (Table 5).

\section{Associated Risk Factors with the Magnitude of Bacterial Isolates}

Whereas age, occupation, household income, use of eyeglass, residence, educational status, frequency of face washing, systemic disease, and history of eye trauma were used as possible risk factors for Eye infection in this study. Multivariable logistic regression analysis showed that only three of them were significantly associated with frequency of bacterial isolation from EEI: namely, educational status (including illiterate $(\mathrm{P}=0.005)$, elementary school $(\mathrm{P}=0.002)$ and pre-school children $(\mathrm{P}=0.001))$ from the demographic data; and previous history of eye surgery $(\mathrm{P}=0.045)$ and systemic disease $(\mathrm{P}=0.006)$ from the clinical data (Table 6).

\section{Discussions}

The overall prevalence of bacterial External eye infection in this study was 175/323 (54.2\%). Similar findings were observed in a prior study done in Ethiopia, from Addis Ababa (54.9\%) ${ }^{26}$ and Gondar (60.8\%); ${ }^{28}$ from India, (58.8\%) and $54.6 \%{ }^{8}$ were reported. However, a relatively lower prevalence was reported in Hawassa, Ethiopia $(48.8 \%)^{29}$ and South India $(46.3 \%){ }^{30}$

On the other hand, a relatively higher prevalence of bacterial isolate of external Eye infection was reported in Ethiopia, from Jimma (74.7\%) ${ }^{4}$ and other countries such as Saudi Arabia (78.7\%). ${ }^{10}$ The varying degree of isolation from one place to another might be due to differences in the distribution of bacterial aetiology, the health of the cornea, geographic location and climate, and also tends to vary somewhat over time. ${ }^{4}$ Moreover, most of our study participants were urban settlers so infection prevention practice in that different settings might be lower compared to the study participants in rural areas.

In the present study, statistically significant associations were observed between external Eye infection and history of systemic disease $(P=0.006)$, history of previous eye surgery $(P=0.045)$ and elementary school level $(P=0.005)$, being preschool children $(P=0.002)$ and being illiterate $(p=0.001)$. However, there were no significant associations between external Eye bacterial infection and the remaining independent variables. Comparable findings were reported from different parts of the world. For example, the reported results from Australia, ${ }^{31}$ Taiwan $^{32}$ and India ${ }^{33}$ showed that $^{3}$ systemic disease and previous eye surgery were the most common predisposing risk factors for bacterial isolates of EEI.

In this study, the predominant type of external eye infection was Blepharitis $122(37.8 \%)$, followed by Conjunctivitis $73(22.6 \%)$. This is different from reports by other studies in Ethiopia such as Hawassa, ${ }^{29}$ Borumeda $^{11}$ and Gondar, ${ }^{3}$ where conjunctivitis was reported to be the predominant clinical future followed by Blepharitis. The reason for this discrepancy could be attributed to the nature of most conjunctivitis cases, which are acute and thus require medication at the nearest medical centre. In the case of our study site, most of the patients being in a chronic presentation are usually handled at the referral hospital, the reason for which Blepharitis might remain predominant EEI at our site.

The leading bacterial isolates of EEI were gram-positive cocci. This is supported by several previous reports from Ethiopia, Jimma; ${ }^{4}$ Borumeda; ${ }^{11}$ Gondar, ${ }^{3}$ southern Ethiopia ${ }^{34}$, and countries like Nigeria, ${ }^{15}$ Japan $^{35}$, Rwanda ${ }^{36}$ and India. ${ }^{37}$ CoNS has been in the past overlooked as a cause of severe infections since it is considered normal flora. CoNS has developed as a prominent source of nosocomial bloodstream infections in recent years, owing to an increased usage of intravascular devices and an increase in the number of hospitalized immunocompromised patients. ${ }^{38,39}$ Thus, it is alarming that CoNS was the most predominant pathogen in this study with an overall prevalence of 76/184 (41.3\%). This dominance is in concordant with previous study reports from Ethiopia, Gondar accounting for $27.42 \%,{ }^{28}$ and in Iran the leading bacterial isolates CoNS 90\%. ${ }^{39,40}$ Additionally, CoNS was predominant isolates in EEI in Uganda $65.9 \%$, and Rwanda $51.4 \%$ were reported. ${ }^{36,41}$ 
Table 5 Multidrug Resistance Patterns of Bacterial Isolates from an External Eye Infection at Menelik II Referral Hospital, Ethiopia, 2019

\begin{tabular}{|c|c|c|c|c|c|c|c|c|}
\hline \multirow[t]{2}{*}{ Bacterial Isolates } & \multicolumn{8}{|c|}{ MDR Status of Bacterial Isolates n (\%) } \\
\hline & $\mathbf{R}_{\mathbf{0}}$ & $\mathbf{R}_{\mathbf{I}}$ & $\mathbf{R}_{\mathbf{2}}$ & $\mathbf{R}_{\mathbf{3}}$ & $\mathbf{R}_{\mathbf{4}}$ & $\mathbf{R}_{\mathbf{5}}$ & $\mathbf{R}_{\mathbf{6}}$ & $\mathbf{R}_{\mathbf{7}}$ \\
\hline \multicolumn{9}{|l|}{ Gram-positive isolates } \\
\hline S. aureus & $\mathrm{I}(\mathrm{I} .5)$ & $8(12)$ & $13(19)$ & $22(32.8)$ & $9(13.4)$ & $12(17.9)$ & $2(3.0)$ & 0 \\
\hline CoNS & 0 & 0 & $6(8.0)$ & $8(10.5)$ & $20(26.3)$ & $25(33.0)$ & $15(19.7)$ & $2(2.6)$ \\
\hline S. pneumoniae & $3(49.9)$ & 0 & $\mathrm{I}(\mathrm{I7})$ & $\mathrm{I}(\mathrm{I} 6.7)$ & $\mathrm{I}(\mathrm{I} 6.7)$ & 0 & 0 & \\
\hline$B$ hemolytic Streptococci & 0 & 0 & 0 & $I(100)$ & 0 & 0 & 0 & 0 \\
\hline Streptococcus viridans & $\mathrm{I}(6.3)$ & $6(38)$ & $4(25)$ & $3(18.7)$ & $2(12.5)$ & 0 & 0 & 0 \\
\hline Enterococcus Species & 0 & $4(80)$ & $I(20)$ & 0 & 0 & 0 & 0 & 0 \\
\hline Total n (\%) & $5(2.9)$ & $18(11)$ & $25(I 5)$ & $35(20.5)$ & $32(18.1)$ & $37(21.6)$ & $17(9.9)$ & $2(1.2)$ \\
\hline \multicolumn{9}{|l|}{ Gram-negative isolates } \\
\hline Escherichia coli & 0 & 0 & 0 & 0 & $I(100)$ & 0 & 0 & 0 \\
\hline Klebsiella Species & 0 & 0 & 0 & $2(33.3)$ & $3(50)$ & $I(16.7)$ & 0 & 0 \\
\hline Proteus Species & 0 & 0 & 0 & 0 & 0 & $2(100)$ & 0 & 0 \\
\hline$P$. aeruginosa & 0 & 0 & $\mathrm{I}(100)$ & 0 & 0 & 0 & 0 & 0 \\
\hline Acinetobacter Species & 0 & 0 & 0 & $I(50)$ & $I(50)$ & 0 & 0 & 0 \\
\hline Providencia stuartii & 0 & 0 & 0 & 0 & $I(100)$ & 0 & 0 & 0 \\
\hline Total n (\%) & 0 & 0 & $\mathrm{I}(7.7)$ & $3(23.1)$ & $6(46.1)$ & $3(23.1)$ & 0 & 0 \\
\hline Over all n (\%) & $5(2.7)$ & $18(9.8)$ & $26(14.1)$ & $38(20.6)$ & $38(20.6)$ & $40(21.7)$ & $17(9.2)$ & $2(1.1)$ \\
\hline
\end{tabular}

Abbreviations: R0, sensitive to all antimicrobials; RI, resistant to I antimicrobial; R2, resistant to 2 antimicrobials; R3, resistant to 3 antimicrobials; R4, resistant to 4 antimicrobials; R5, resistant to 6 antimicrobials; R7, resistant to 7 antimicrobials. 
Table 6 Multivariate Logistic Regression Analysis of Factors Associated Among Patients with External Eye Infection at Menelik II Referral Hospital, Ethiopia, 20I9

\begin{tabular}{|c|c|c|c|c|c|c|c|}
\hline \multirow[t]{2}{*}{ Variables } & \multirow[t]{2}{*}{ Categories } & \multicolumn{3}{|c|}{ Bacterial Isolates } & \multirow[t]{2}{*}{ COR $(95 \% \mathrm{Cl})$} & \multirow[t]{2}{*}{ AOR $(95 \% \mathrm{Cl})$} & \multirow[t]{2}{*}{ P-value } \\
\hline & & Yes (\%) & No $(\%)$ & $\mathbf{N}(\%)$ & & & \\
\hline \multirow[t]{5}{*}{ Age group } & $\leq 15$ & $28(62.2)$ & $17(37.8)$ & $45(13.9)$ & 1.0 (references) & 1.0 & \\
\hline & $16-30$ & $34(51.5)$ & $32(48.5)$ & $66(20.4)$ & & & \\
\hline & $31-45$ & $30(43.5)$ & $39(56.5)$ & $69(21.4)$ & $2.538(1.25-5.16)$ & $1.18(0.5 \mathrm{I}-2.74)$ & 0.7 \\
\hline & $46-60$ & $42(51.9)$ & $39(48.1)$ & $8 I(25.1)$ & & & \\
\hline & $>60$ & $4 I(66.1)$ & $21(33.9)$ & $62(19.2)$ & & & \\
\hline \multirow[t]{5}{*}{ Educational status } & Illiterate & $55(67.9)$ & $26(32.1)$ & $81(25.1)$ & $0.15(0.06-0.37)$ & $0.17(0.05-0.59)$ & 0.005 \\
\hline & Preschool children & 15(83.3) & $3(16.7)$ & $18(5.6)$ & $0.06(0.01-0.27)$ & $0.014(0.0-0.20)$ & 0.001 \\
\hline & Elementary school & $67(61.5)$ & $42(38.5)$ & 109(34) & $0.19(0.08-0.47)$ & $0.190(0.07-0.55)$ & 0.002 \\
\hline & Secondary School & $20(34.5)$ & $38(65.5)$ & $58(18.0)$ & $0.02(0.07-0.50)$ & $0.02(0.07-0.57)$ & \\
\hline & College and Above & $18(31.6)$ & $39(68.4)$ & $57(17.6)$ & I.0(references) & 1.0 & \\
\hline \multirow[t]{4}{*}{ House hold monthly income } & $\leq 600$ Birr & $13(76.5)$ & $4(23.5)$ & $17(5.3)$ & $0.20(0.06-0.70)$ & & \\
\hline & 600-1500 Birr & $89(66.9)$ & $44(33.1)$ & $133(4 \mid .2)$ & $0.32(0.17-0.63)$ & & \\
\hline & $1500-4500$ Birr & $52(43.3)$ & $68(56.7)$ & $120(37)$ & & & \\
\hline & $>4500$ Birr & $21(39.6)$ & $32(60.4)$ & $53(16.4)$ & 1.0 (references) & 1.0 & \\
\hline \multirow[t]{2}{*}{ Previous eye surgery } & Yes & $44(74.6)$ & $15(25.4)$ & $59(18.3)$ & $0.357(0.18-0.63)$ & $0.47 \mathrm{I}(0.23-0.98)$ & 0.045 \\
\hline & No & $|3|(49.6)$ & 133(50.4) & $264(81.7)$ & 1.0 (references) & 1.0 & \\
\hline \multirow[t]{2}{*}{ Systemic disease } & Yes & $20(80.0)$ & $5(20.0)$ & $25(7.7)$ & $0.271(0.1-0.74)$ & $0.21(0.07-0.64)$ & 0.006 \\
\hline & No & $155(52.0)$ & 143(48.0) & $298(92.3)$ & 1.0 (references) & 1.0 & \\
\hline \multirow[t]{4}{*}{ Face washing frequency } & Sometimes & $26(72.2)$ & $10(27.8)$ & $36(11.1)$ & $0.32(0.13-0.82)$ & $0.22(0.10-0.71)$ & \\
\hline & One Times & $65(54.6)$ & $54(45.4)$ & $119(36.8)$ & & & \\
\hline & Two times & $64(51.6)$ & $60(48.4)$ & 124(38.4) & & & \\
\hline & More than 2 times & $20(45.5)$ & $24(54.5)$ & $44(13.6)$ & 1.0 (references) & 1.0 & \\
\hline
\end{tabular}


The data of the present study showed that the predominant bacteria from blepharitis cases were CoNS followed by $S$. aureus accounting for 36/71 (50.7\%) and 23/71 (32.4\%), respectively. This is in agreement with the previous study done in Ethiopia, Hawassa, from blepharitis cases (CoNS 35.6\% and S. aureus 32\%). ${ }^{29}$ More bacterial isolates were found in the eyelid sample compared to the conjunctival sample due to bacterial colonization and repeated penetration from adjacent skin to the edge of the eyelid. ${ }^{5,7,8}$ In the Dacryocystitis case, S. aureus and CoNS account equally for 30.4\% (7/ 23). The result is supported by several reports from Ethiopia, Gondar CoNS $29.0 \%$ and S. aureus $29.4 \% ;{ }^{14}$ CoNS $25.0 \%$ and S. aureus $17.1 \%{ }^{1}$

In regards to sensitivity, significant amounts of gram-positive isolates had lower sensitivity to penicillin (6.0\%) and ampicillin (20.0\%). Among those, S. aureus isolates, 65/67 (97.0\%) and 58/67 (86.5\%) were susceptible to Tobramycin and Gentamicin, respectively. In the current study, Tobramycin was the only antibiotic to which CoNS isolates were highly sensitive accounting for 70/76 (92.1\%). However, higher proportions of CoNS isolates indicated to be lower sensitivity to many of the commonly used antibiotics; Penicillin 1/76 (1.3\%), Erythromycin 13/76 (17.1\%) and Ciprofloxacin 31/76 (40.8\%). This is comparable with similar studies done in Rwanda in regards to Erythromycin (29\%) and Ciprofloxacin (41.2\%) were reported to be lower. ${ }^{36}$ Improper selection of antibiotics, improper dosages, and inadequate adherence to treatment can all play an important role in increasing drug tolerance. ${ }^{17,18,29}$

Among the $S$. aureus isolates, 65/67 (97.0\%) and 58/67 (86.5\%) were susceptible to tobramycin and gentamicin, respectively. However, higher proportions of the $S$. aureus isolates were lower sensitivity to penicillin $2 / 67(3.0 \%)$ and erythromycin 21/67 (31.3\%). In agreement with another study report from Ethiopia, Gondar had 3.1\% sensitivity to penicillin; but in other ways, higher sensitivity to Erythromycin $71.9 \%$ was reported. ${ }^{3}$ The lower sensitivity to Erythromycin in our study might be a result of time and geographic variation as well as study populations. Furthermore, the prevalence of MRSA infection, as determined based on the resistance pattern of Cefoxitin in this study was $23 / 67$ (34.3\%). Although the gold standard for identifying MRSA is the detection of the mecA gene, ${ }^{42}$ the study result depended only on the detection of Cefoxitin since genotypic tests are expensive. Formerly, a study in Taiwan using molecular characterization, and Antibiogram of MRSA demonstrated that patients with bacterial conjunctivitis simultaneously had $S$. aureus isolates, $34 / 59(57.6 \%)$ of them were MRSA positive. ${ }^{43}$ On the other hand, based on Cefoxitin resistance status a report from Brazil 56/566 (9.9\%) S. aureus isolates were resistant to methicillin and concluded that MRSA is yet an infrequent cause of EEI in Brazil. ${ }^{44}$ This shows a significant variation in the prevalence of MRSA eye infections geographically and at different time points. ${ }^{3}$ This may reflect real differences in the prevalence of MRSA, the standards of microbiology tests, or even epidemiological changes over time.

The drug susceptibility status of gram-negative bacterial isolates to Tobramycin and Gentamicin were 13/13 (100\%) and 11/13 (84.6\%), respectively. Additionally, 10/13 (76.9\%) of gram-negative bacterial isolates were susceptible to Amikacin and ciprofloxacin. This is in agreement with the previous studies from Pakistani. ${ }^{38}$

Prevalence of multidrug resistance (MDR) is bacterial isolate at least having one or more commonly prescribed antimicrobials resistant from three or more classes of antibiotics. ${ }^{27}$ MDR was observed in 135/184 (73.4\%) of the bacterial isolates. The overall MDR pattern of the gram-negative bacterial isolates was $12 / 13(92.3 \%)$. This is in agreement with the previous study reports with a higher prevalence of MDR documented from Gondar. ${ }^{30}$ However, in Hawassa relatively low prevalence of multidrug resistance 100/143 (69.9\%) was reported. ${ }^{31}$

Among gram-positive isolates, 123/171 (72\%) had multidrug resistance. This indicates that most of the isolates had shown higher resistance to commonly used antibiotics. This is because of lack of access to microbiology laboratory in most health institutions, clinicians' use broad-spectrum or empirical therapy; that concerns' the risk of multidrug resistance expansion. ${ }^{4,11}$ The higher prevalence of MDR in our study might be due to the irrational use of antimicrobial agents and empirical therapy, which can result in the emergence of bacterial strains that show multidrug resistance. ${ }^{27}$ Since, Menelik II Hospital is a national referral centre, where most of the patients coming for medical attention are those who have already started and failed medication to common topical antimicrobial therapy.

\section{Limitation of the Study}

The limitation of our study was that those bacteria which are not easily cultured by routine laboratory diagnosis but that cause Eye infections such as Chlamydia trachomatis, Corynebacterium species and anaerobic bacteria were not 
investigated. Additionally, genotyping analysis was not performed, due to resource constraints. Fungal agents did not address in this study due to resource constraints and the availability of the facility.

\section{Conclusions}

The main clinical future of the external eye was blepharitis, followed by conjunctivitis in patients with the external eye. Low education, systemic disease, and history of eye surgery were significantly associated with the presence of bacterial isolates. Overall, CoNS, Staphylococcus aureus, Viridans streptococcus, and Klebsiella species were the predominant isolates. The majority of Gram-positive and all Gram-negative isolates showed some degree of multidrug resistance.

The overall antibiotic susceptibility status of the bacterial isolate indicates that chloramphenicol, following tobramycin and gentamicin, should be considered as the optimal drug for empirical treatment. Microbiological isolation and antibiotic susceptibility testing should be performed as a routine diagnosis of eye infections to reduce the increased incidence of multidrug-resistant strains. In general, the increased pattern of drug resistance seen in this and other studies indicates the need for continued bacterial monitoring and further research.

\section{Abbreviations}

AOR, Adjusted Odds Ratio; ATCC, American Type Culture Collection; BHIB, Brain Heart Infusion Broth; CI, Confidence Interval; CoNS, Coagulase Negative Staphylococcus; COR, Crude Odds Ratio; EEI, External Eye Infection; MDR, Multi-Drug Resistance; MRSA, Methicillin-Resistant Staphylococcus aureus.

\section{Data Sharing Statement}

The first author (Asmamaw Nitsuh) can provide data to support the findings of this paper upon request. The full length of the thesis is found on the Addis Ababa University research Repository website: http://etd.aau.edu.et/bitstream/handle/ 123456789/21296/Asmamaw\%20Nitsuh.pdf?isAllowed=y\&sequence $=1$

\section{Consent to Participation and Ethics Approval}

The AAU College of Health Sciences, Department of Microbiology, Immunology, and Parasitology, and the Research Ethics Review Committee gave their approval. Addis Ababa Regional Health Bureau Research \& Emergency Management, as well as Menelik II Referral Hospital, provided official collaboration letters. Before data was collected, the study participants/guardians gave their written informed consent and assent.

\section{Acknowledgment}

We would like to acknowledge Addis Ababa University for financial support, Addis Ababa Health Bureau facilities to conduct this study, and Yikatit 12 Hospital Microbiology Laboratory unit for providing laboratory spaces. Menelik II Referral Hospital Ophthalmology unit and all study participants are acknowledged for their cooperation during sample collection.

\section{Funding}

The study was supported by the Addis Ababa University Postgraduate Students Research fund.

\section{Disclosure}

The authors report no conflicts of interest in this work.

\section{References}

1. Belyhun Y, Moges F, Endris M, et al. Ocular bacterial infections and antibiotic resistance patterns in patients attending Gondar Teaching Hospital, Northwest Ethiopia. BMC Res Notes. 2018;11(1):597-603. doi:10.1186/s13104-018-3705-y

2. Sherwal BL, Verma AK. Epidemiology of ocular infection due to bacteria and fungus: a prospective study. JK Sci. 2008;10(3):127-131.

3. Getahun E, Gelaw B, Assefa A, Assefa Y, Amsalu A. Bacterial pathogens associated with external ocular infections alongside the eminent proportion of multidrug-resistant isolates at the University of Gondar Hospital, northwest Ethiopia. BMC Ophthalmol. 2017;17(1):151-160. doi:10.1186/ s12886-017-0548-6 
4. Tesfaye T, Beyene G, Gelaw Y, Bekele S, Saravanan M. Bacterial profile and antimicrobial susceptibility pattern of external ocular infections in Jimma University Specialized Hospital, Southwest Ethiopia. Am J Infect Dis Microbiol. 2013;1(1):13-20.

5. Armstrong RA. The microbiology of the eye. Ophthal Physiol Opt. 2000;20(6):429-441. doi:10.1111/j.1475-1313.2000.tb01121.x

6. Alzahrani SM, Al-Ghamdi SA, Abdelaal AM, Abbas EA, Khan MA, Al-Amri AW. The bacterial spectrum of external ocular infections: prevalence and associated in vitro antimicrobial susceptibility and resistance in a tertiary care hospital. Int J Adv Res. 2018;6(1):869-878. doi:10.21474/ IJAR01/6296

7. Wang N, Yang Q, Tan Y, Lin L, Huang Q, Wu K. Bacterial spectrum and antibiotic resistance patterns of ocular infection: differences between external and intraocular diseases. $J$ Ophthalmol. 2015;1(1):1-7.

8. Bharathi MJ, Ramakrishnan R, Shivakumar C, Meenakshi R, Lionalraj D. Etiology and antibacterial susceptibility pattern of community-acquired bacterial ocular infections in a tertiary eye care hospital in south India. Indian J Ophthalmol. 2010;58(6):497-507. doi:10.4103/0301-4738.71678

9. Willcox M. Review of resistance of ocular isolates of Pseudomonas aeruginosa and staphylococci from keratitis to ciprofloxacin, gentamicin and cephalosporins; Vision CRC, Sydney, NSW, Australia. Clin Exp Optom. 2011;94(2):161-168. doi:10.1111/j.1444-0938.2010.00536.x

10. Shahaby AF, Alharthi AA, Tarras AE. Potential bacterial pathogens of red-eye infections and their antibiotic susceptibility patterns in Taif, KSA. Int J Curr Microbiol App Sci. 2015;4(11):383-393.

11. Shiferaw B, Gelaw B, Assefa A, Assefa Y, Addis Z. Bacterial isolates and their antimicrobial susceptibility pattern among patients with external ocular infections at Borumeda hospital, Northeast Ethiopia. BMC Ophthalmol. 2015;15(1):103-110. doi:10.1186/s12886-015-0078-z

12. Bertino JS. Impact of antibiotic resistance in the management of ocular infections: the role of current and future antibiotics. Clin Ophthalmol. 2009;3(1):507-521. doi:10.2147/OPTH.S5778

13. Blanco C, Nunez MX. Antibiotic susceptibility of staphylococci isolates from patients with chronic conjunctivitis: including associated factors and clinical evaluation. J Ocul Pharmacol Ther. 2013;29(9):803-808. doi:10.1089/jop.2013.0040

14. Assefa Y, Moges F, Endris M, et al. Bacteriological profile and drug susceptibility patterns in dacryocystitis patients attending Gondar University Teaching Hospital, Northwest Ethiopia. BMC Ophthalmol. 2015;15(1):34-41. doi:10.1186/s12886-015-0016-0

15. Ubani UA. Bacteriology of external ocular infections in Aba: South Eastern, Nigeria. Clin Exp Optom. 2009;92(6):482-489. doi:10.1111/j.14440938.2009.00425.x

16. Brown L. Resistance to eye antibiotics: an overview. Clin Exp Optom. 2007;90(4):258-262. doi:10.1111/j.1444-0938.2007.00154.x

17. Rahman ZA, Harun A, Hasan H, et al. Eye surface infections in the northeastern State of Malaysia: a 10-year review of Bacterial isolates and antimicrobial susceptibility. Ey Con Len. 2013;39(5):355-360. doi:10.1097/ICL.0b013e3182a3026b

18. Stratton CW. Dead bugs do not mutate Susceptibility issues in the emergence of bacterial resistance. Emerg Infect Dis. 2003;9(1):10-16. doi:10.3201/eid0901.020172

19. Gaynor BD, Chidambaram JD, Cevallos V, et al. Topical eye antibiotics induce bacterial resistance at extraocular sites. Br J Ophthalmol. 2005;89 (1):1097-1099. doi:10.1136/bjo.2005.068981

20. Umamageswari S, Jeya M, Suja C. Study of a bacterial and fungal profile of external Eye infections in a tertiary care hospital. Nation J Lab Med. 2013;2(3):6-10.

21. Bitew A, Siraj M, Teklebirhan G. Clinical and microbiological profile of keratitis in Menelik II Memorial Hospital, Addis Ababa, Ethiopia. EC Microbiol. 2018;14(4):173-180.

22. Sharma S. Diagnosis of infectious diseases of the eye. Eye. 2012;26(2):177-184. doi:10.1038/eye.2011.275

23. Clinical Laboratory Standard Institute. Performance Standards for Antimicrobial Disk Susceptibility Testing. 27th ed. Vol. 37. Pennsylvania, USA: CLSI supplement M100; 2017:M02-A12.

24. The European Committee on Antimicrobial Susceptibility Testing. Breakpoint tables for interpretation of MICs and zone diameters. EUCAST guide. Version 8.1; 2018. Available from: http://www.eucast.org. Accessed February 22, 2022.

25. Magiorakos A, Srinivasan A, Carey R, et al. Multidrug-resistant, extensively drug-resistant and pan drug-resistant bacteria: an international expert proposal for interim standard definitions for acquired resistance. Clin Microbiol Infect. 2012;18(3):268-281. doi:10.1111/j.1469-0691.2011.03570.x

26. Teweldemedhin M, Saravanan M, Gebreyesus A, Gebreegziabiher D. Eye bacterial infections at Quiha Ophthalmic Hospital, Northern Ethiopia: an evaluation according to the risk factors and the antimicrobial susceptibility of bacterial isolates. BMC Infect Dis. 2017;17(1):207-216. doi:10.1186/ s12879-017-2304-1

27. Aklilu A, Bitew A, Dessie W, et al. Prevalence and drug susceptibility pattern of bacterial pathogens from ocular infection in St. Paul's Hospital Millennium Medical College, Ethiopia. J Bacteriol Mycol. 2018;5(8):1085-1093.

28. Muluye D, Wondimeneh Y, Moges F, Nega T, Ferede G. Types and drug susceptibility patterns of bacterial isolates from eye discharge samples at Gondar University Hospital, Northwest Ethiopia. BMC Res Notes. 2014;7(1):292-296. doi:10.1186/1756-0500-7-292

29. Amsalu A, Abebe T, Mihret A, Delelegne D, Tadesse E. Potential bacterial pathogens of external ocular infections and their antibiotic susceptibility pattern at Hawassa University Teaching and Referral Hospital, Southern Ethiopia. Afr J of Microbiol Res. 2015;9(14):1012-1119. doi:10.5897/ AJMR2014.7282

30. Rajesh S, Divya B, Aruna V. Microbiological profile of external ocular infections in a tertiary care hospital in South India. Int J Curr Microbiol. 2017;6(7):4343-4352. doi:10.20546/ijcmas.2017.607.452

31. Green M, Apel A, Stapleton F. Risk factors and causative organisms in microbial keratitis: epidemiology of keratitis in Queensland, Australia. Cornea. 2008;27(1):22-27. doi:10.1097/ICO.0b013e318156caf2

32. Lin TY, Yeh LK, Ma DH, et al. Risk factors and microbiological features of patients hospitalized for microbial keratitis: a 10-Year Study in a referral centre in Taiwan. Medicine. 2015;94(43):1-6. doi:10.1097/MD.0000000000001905

33. Reddy JC, MurthY SI, Reddy AK, Garg P. Risk factors and clinical outcomes of bacterial and fungal scleritis at a tertiary eye care hospital. Middle East Afr J Ophthalmol. 2015;22(2):203-211. doi:10.4103/0974-9233.150634

34. Aweke T, Dibaba G, Ashenafi K, Kebede M. Bacterial pathogens of exterior ocular infections and their antibiotic vulnerability pattern in Southern Ethiopia. Afr J Immun Res. 2014;1(2):19-25.

35. Deguchi H, Kitazawa K, Kayukawa K, et al. The trend of resistance to antibiotics for eye infection of Staphylococcus aureus, coagulase-negative staphylococci, \&Corynebacterium compared with 10-years previous: a retrospective observational study. PLoS One. 2018;13(9):1-10. doi:10.1371/ journal.pone. 0203705

36. Semanyenzi SE, Abahuje S. normal conjunctival flora as seen in adult patients at Kigali university teaching hospital. RMJ. 2013;70(2):22-24. 
37. Ipe A, Navaneetha N, Skariah R. Profile of patients with ocular infections attending the outpatient department of a tertiary care centre in South India. Int J Res Med Sci. 2016;4(7):3027-3031.

38. Hsiao C, Sun C, Yeh L, et al. Shifting trends in bacterial keratitis in Taiwan: a 10-year review in a tertiary-care hospital. Cornea. 2016;35(3):313317. doi: $10.1097 /$ ICO.0000000000000734

39. Natoli S, Fontana C, Favaro M, et al. Characterization of coagulase-negative staphylococcal isolates from blood with reduced susceptibility to glycopeptides and therapeutic options. BMC Infect Dis. 2009;9:83. doi:10.1186/1471-2334-9-83

40. Aghadoost D, Khorshidi A. Antibiotic resistance patterns of ocular surface bacterial flora at Martini hospital Iran. Iran J Clin Infect Dis. 2007;2 (3): 133-137.

41. Mshangila B, Paddy M, Kajumbula H, Ateenyi-Agaba C, Kahwa B, Seni J. External ocular surface bacterial isolates and their antimicrobial susceptibility patterns among pre-operative cataract patients at Mulago National Hospital in Kampala, Uganda. BMC Ophthalmol. 2013;13(1):7176. doi:10.1186/1471-2415-13-71

42. Brown DF. Detection of methicillin/oxacillin resistance in staphylococci. J Antimicrob Chemother. 2001;48(Suppl S1):65-70. doi:10.1093/jac/48. suppl_1.65

43. Kang Y, Hsia C, Yeh L, et al. Methicillin-resistant S. aureus ocular infection in Taiwan. Medicine. 2015;94(42):1-8. doi:10.1097/ MD.0000000000001620

44. Vola ME, Moriyama AS, Lisboa R, et al. Prevalence and antibiotic susceptibility of methicillin-resistant Staphylococcus aureus in ocular infections. Arq Bras Oftalmol. 2013;76(6):350-353. doi:10.1590/S0004-27492013000600006

\section{Publish your work in this journal}

Infection and Drug Resistance is an international, peer-reviewed open-access journal that focuses on the optimal treatment of infection (bacterial, fungal and viral) and the development and institution of preventive strategies to minimize the development and spread of resistance. The journal is specifically concerned with the epidemiology of antibiotic resistance and the mechanisms of resistance development and diffusion in both hospitals and the community. The manuscript management system is completely online and includes a very quick and fair peer-review system, which is all easy to use. Visit http://www.dovepress.com/testimonials.php to read real quotes from published authors.

Submit your manuscript here: https://www.dovepress.com/infection-and-drug-resistance-journal 